This item was submitted to Loughborough's Research Repository by the author.

Items in Figshare are protected by copyright, with all rights reserved, unless otherwise indicated.

\title{
Customised design and manufacture of protective face masks combining a practitioner-friendly modelling approach and low-cost devices for digitising and additive manufacturing
}

\section{PLEASE CITE THE PUBLISHED VERSION}

http://dx.doi.org/10.1080/17452759.2014.958648

\section{PUBLISHER}

(C) Taylor \& Francis

\section{VERSION}

SMUR (Submitted Manuscript Under Review)

\section{PUBLISHER STATEMENT}

This work is made available according to the conditions of the Creative Commons Attribution-NonCommercialNoDerivatives 4.0 International (CC BY-NC-ND 4.0) licence. Full details of this licence are available at: https://creativecommons.org/licenses/by-nc-nd/4.0/

\section{LICENCE}

CC BY-NC-ND 4.0

\section{REPOSITORY RECORD}

Cazon, Aitor, Jon Aizpurua, Abby Paterson, Richard Bibb, and lan Campbell. 2014. "Customised Design and Manufacture of Protective Face Masks Combining a Practitioner-friendly Modelling Approach and Low-cost Devices for Digitising and Additive Manufacturing". Loughborough University. https://hdl.handle.net/2134/16457. 


\title{
Customised design and manufacture of protective face masks combining a practitioner-friendly modelling approach and low-cost devices for digitising and
}

\section{Additive Manufacturing}

\author{
Aitor Cazon \\ Department of Mechanical Engineering, Tecnun-University of Navarra, Spain Paseo \\ Manuel Lardizábal 13, 20.018 Donostia-San Sebastián, Spain. Email: acazon@tecnun.es \\ Jon Aizpurua \\ Department of Mechanical Engineering, Tecnun-University of Navarra, Spain Paseo \\ Manuel Lardizábal 13, 20.018 Donostia-San Sebastián, Spain. +34 943219 \\ 877.A901073@alumni.tecnun.es \\ Abby Paterson \\ Loughborough Design School, Loughborough University, Leicestershire, LE11 3TU, \\ UK Loughborough University. +44 (0)1509 263171. A.M.Paterson@lboro.ac.uk \\ Richard Bibb \\ Loughborough Design School, Loughborough University, Leicestershire, LE11 3TU, \\ UK Loughborough University.+44 (0)1509 263171. R.J.Bibb@lboro.ac.uk \\ R. Ian Campbell \\ Loughborough Design School, Loughborough University, Leicestershire, LE11 3TU, \\ UK Loughborough University.+44 (0)1509 263171. R.I.Campbell@lboro.ac.uk

\section{Acknowledgements} \\ Thanks to Luis Naval MD, head of Oral and Maxillofacial Surgery Department from \\ Clinica Universidad de Navarra for his help and advices throughout this project.
}

\section{Abstract:}

This project analyses the viability of an efficient modelling approach using a semi-automatic algorithm within a Computer Aided Design (CAD) application in combination with low-cost digitising devices and low-cost Additive Manufacturing (AM) printers when designing and manufacturing patient-specific face masks. The aims of the study were to enable clinical practitioners to utilise the advantages of 3D scanning, CAD and AM without having to be trained to use design/engineering software. Face features were captured using two 3D devices. The resulting meshes were compared via the Hausdorff Distance method. A semiautomatic modelling procedure was developed with 'Rhinoceros' and 'Grasshopper' to model the face mask and customise several features. With that procedure, volunteers modelled a face mask in less than 30 minutes in their first attempt. The resulting virtual mask was manufactured with two AM printers. An initial economic study indicated that the presented approach offers a feasible alternative to the current practices.

Keywords: Face mask, 3D scanning, Additive Manufacturing, 3D printing, CAD 


\section{Introduction}

Facial fracture refers to any injury that results in a broken facial bone, i.e. the nasal bone, as a result of motor vehicle collisions (Hogg et al. 2000), sports accidents (Tanaka et al. 1996) or violence (Le et al. 2001). Face-protective orthosis, and in particular, nose guards are patient-specific splints, preferably with one-piece structure (Ghoseiri et al. 2013), that protect the face during sport activities and reduce post-operative time of inactivity during everyday activities and/or sports by helping the nose not to be damaged while the human body 'welds' the bones again (Bell and Kindsfater 2006; Mondin et al. 2005). There are two main methods of manufacturing protective face masks.

The traditional method is entirely manual (Locke et al. 1991; Powell et al. 1985; Rivers et al. 1979): Firstly, a negative impression (sometimes called moulage) of the face is taken using materials such as plaster, alginate or silicon rubber. Later, a positive replica of the face is then made from the impression typically using plaster or dental stone. Subsequently, a rectangular Low Temperature Thermoplastic (LTT) sheet, typically polycarbonate (PC) of around 2 to 3mm in thickness, is heated until it reaches its softening point and becomes pliable. Then, the positive impression is placed on a vacuum former, the sheet is draped over the positive impression, and a vacuum is applied in order to obtain the impression of the mould on the sheet. Once cool, the LTT sheet is removed from the mould and cut to the final dimensions of the mask by using scissors, a heated knife or a grinding/cutting tool. Finally, holes are cut for the eyes, nostrils and mouth as required, the edges are rounded with abrasives and the straps which hold the mask to the patient's face are attached. This conventional process, widely used among practitioners, is unpleasant for the patient and frequently involves an iterative process if the mask has a poor fit on patient's face, resulting in a time consuming process where much material and clinic time is wasted (Chandra et al. 2004; Lin and Nagler 2003).

In addition to this traditional technique, new technologies have been applied to minimise the abovementioned issues and satisfy patients' needs regarding a proper adjustment of the face mask 
(Deon J. de Beer et al. 2005; Sanghera et al. 2001). These technologies involve three dimensional scanners to capture facial features, Computer Aided Design (CAD) applications to model the mask and Additive Manufacturing (AM) to build the mask layer upon layer from the 3D data model. The capture of facial features by means of non-contact digitising devices implies the capture the patient's face without touching it using optical methods (e.g. laser, structured light, etc.) or by using some passive technology like stereophotogrammetry. The result of all these technologies is the patient's face represented by a collection of virtual points (called a point cloud) or a triangular mesh in a few seconds (Aung et al. 1995; Lin and Nagler 2003). With the virtual face, the face mask can be designed with a number of commercially available Computer Aided Design (CAD) applications. Once the virtual mask is modelled, it may be manufactured by using any AM technology that has been previously used in a number of medical applications, including design and manufacturing of medical splints for ankle-foot (Pallari et al. 2010) (Faustini et al. 2008; Mavroidis et al. 2011) or wrist (Palousek et al. 2014; Paterson 2013). The physical prototype can be later post-processed for particular applications with conventional existing techniques, such as metal spraying for patientspecific face masks necessary for radiography applications in cancer treatment (Deon J. de Beer et al. 2005). Another alternative is to directly manufacture the virtual face using any available AM technology and use that face as mould later in the vacuum former to create the mask (Bibb et al. 2004).

When compared to the traditional approach, the new technological methodology presents several advantages but also some drawbacks. As advantages, the trauma experienced by the patient is eliminated by avoiding any physical contact as with the conventional approach, it eliminates inaccuracy issues due to patient's movement while setting the alginate and the plaster bandages, the fit of the mask to the face is improved and the practitioner can deliver a customised mask to fulfil the patient's needs. 
However, there are a number of potential disadvantages. Firstly, there are some well documented problems when scanning human face. Poor quality data can result by the presence of hair (eyebrows or beard for example) that could affect the design of a mask that perfectly fits to the patient's face (Bibb et al. 2000). Additionally, the investment required for specific 3D scanners for human face is significant and, in most of cases, they require certain knowledge about the technology in order to a good quality virtual face. Moving to the modelling process, there are also some drawbacks to mention. CAD technologies are becoming more popular for medical application and practitioners are willing for technological advances in their job that allows them to model a face mask to suit the patient's needs. However, in many cases, they find that the training and skill required for the CAD modelling process of customised masks could be time and cost prohibitive. This point has as consequence that many practitioners favourable to this new approach must completely rely on external modellers to get the job done, being imperative that a good communication flow between designer and practitioner should be established to avoid misunderstandings that could lead to design flaws in the mask. In order to fill this gap and minimize the modelling efforts so the own practitioner can model customised splints, Paterson (2013) researched into a 3D CAD strategy to design custom-made wrist splints in order to evaluate novel features only available through AM. This included the possibility of open, lattice-type structures that aimed to reduce weight, provide aesthetic patterns, and maintain a dry splint interior by increasing the ventilation subsequently reducing the moisture trapped between skin and splint. Regarding the AM process, some disadvantages are present through the process like the investment required for the AM machine (3D printer). AM materials may also be more expensive than those used in the traditional practice. However, in recent years the expiry of key patents has led to proliferation of 3D printer manufacturers resulting in a dramatic reduction in machine and material costs. 
This work aimed to confirm that the combination of existing tools of three-dimensional digitisation, CAD and Additive Manufacturing can lead to a technologically feasible, practitionerfriendly and cost-effective solution to improve the traditional design and manufacturing process of patient-specific protective face masks. More specifically, a user-friendly semi-automatic algorithm within a Computer Aided Design (CAD) application was developed for the customization of the mask. The aim was that this semi-automation would enable clinicians to be able to model a face mask easily without having to be highly proficient in CAD skills. Additionally, the combination of a high-cost scanner and 3D printer were compared in terms of accuracy and cost against their lowcost counterpart and against the traditional approach. 


\section{Methods}

The entire methodology was divided into three phases; each one involved several steps. A graphical scheme of the workflow is depicted in Figure 1. The process started with the digitisation of the patient's face to produce the virtual mesh. Then, a personalised CAD modelling file was created to generate a customised face mask based on the virtual face. The process ended with the manufacture of the physical prototype.

\section{Digitising process}

The digitising process of the patient's face was performed with two capturing devices (Figure 2). The first one was a vertical face scanner Qlonerator Pro 200 from 3dMD (3dMD, Atlanta, Georgia, USA). This system works on the principal of stereo photogrammetry and uses eight cameras in a multi-pod configuration (four in each pod) along with a projected pattern to acquire the patient's face. The scanner also generates images containing high resolution textures of the face. The range of the scanner is 180 degrees -from ear to ear- while the capture speed is 2 milliseconds, with precision resolution of less than $0.2 \mathrm{~mm}$. The suitability of this device for facial scanning was empirically discussed by Boehnen and Flynn (Boehmen and Flynn 2005) by comparing 60 scans taken from 6 different volunteers. The Qlonerator generated very accurate points showing a mean global accuracy of $0.106 \mathrm{~mm}$. For the digitising process, a volunteer was seated on a movable chair and his face was positioned within the focal volume of overlap which the cameras require. At this position the volunteer was approximately 1 metre away from the cameras. The volunteer was relaxed with his mouth closed and his head in a natural position. The data capture process was not invasive or harmful to the volunteer. Prior to the data acquisition, the scanner was calibrated following the procedure suggested by the manufacturer. The capturing process was made in a closed and illuminated room. After the capturing process, the textured 3D model was generated at the support computer and exported to Virtual Reality Modelling Language (VRML) file format where the face was virtually defined by a collection of points and triangles (a triangular faceted 
mesh).

Additionally, a second capturing device was used; the Sense 3D scanner from 3D Systems (Rock Hill, South Carolina, USA). This low-cost scanner (approximately 400€) projects a pattern onto the surroundings using an infrared Class I eye-safe laser. The scanner also has two cameras; one captures the geometry and the other captures the colour. According to manufacturer datasheet, the spatial resolution at $0.5 \mathrm{~m}$ is $0.9 \mathrm{~mm}$ while its depth resolution is $1 \mathrm{~mm}$ at the same distance. For the scanning process, the volunteer was seated on a chair while a second person moved the scanner around his face in a freehand manner to capture the whole surface. After scanning, the geometry was exported via the Stereolithography (STL) format where the face was defined by means of points and triangles (also in the form of a triangular faceted mesh).

The resulting mesh from the 3dMD scanner had 66,535 vertices, 132,074 triangles and its size was 13.26 Megabytes whilst the scan from the Sense scanner was defined by 127,567 vertices and 253,032 triangles with a file size of 12.35 Megabytes (Figure 3).

\section{CAD Modelling process}

After the digitisation, two masks were modelled: one based on the 3dMD mesh and another with the Sense scanner mesh. Each mesh was taken as is from the scanning process and they were not repaired, cleaned or smoothed. Each face mask was designed using the Rhinoceros 5.0 CAD application and the integrated plug-in Grasshopper version 0.9.0061 (Robert McNeel \& Associates, Seattle, Washington, USA). Grasshopper is a graphical programing interface widely used in architectural design that help users to create parametric 3D geometry by dragging components onto a canvas and visualise the modelling results within Rhino environment. For this study, the process of modelling and customising of the face mask was divided into nine consecutive stages, all of them programmed in Grasshopper with a user-friendly interface where possible (Figure 4). The resulting application was called DeMask (Design of a Mask). 
The first stage involved loading and orientating the face mesh into an ideal position within Rhinos. Subsequently, a series of lines, previously drawn in Rhinoceros (Figure 5 a) were projected onto the mesh (b); the position of the lines was adjustable using several sliders in Grasshopper to refine their placement relative to the facial features, such as the eyes and the nose. The projected curves were used to form a blended surface to depict the mask topography (b, c). Next, a planar curve previously created in Rhinoceros (d) was used as a trimming feature to create a refined shape to the face mask (e).

The customisation process continued by allowing the user to adjust several aesthetic features of the mask such as the shape and number of holes for the eyes (Figure 6). The number of fastening holes for the rubber strips was also integrated as a parametric feature, as well as the shape (e.g., circular, elliptical, triangular, rectangular, pentagonal, hexagonal) and quantity of transpiration holes through the mask (Figure 7). For this study, the face mask with two holes for the eyes and a circular hole pattern for transpiration (ventilation) was manufactured.

\section{Manufacturing process}

The physical prototype of the face mask based on the 3dMD scanner was manufactured using Fused Deposition Modelling (FDM). The FDM system chosen was the HP DesignJet Color 3D (Hewett Packard, Palo Alto, California, USA) which features 0.254 mm thick layers. It uses thermoplastic filaments with approximately 1mm diameter and made of acrylonitrile-butadiene-styrene (ABS) copolymer. In the FDM process, the filaments are heated and then extruded in single paths to form each layer of the build. A second nozzle deposits the necessary support material which is soluble and removed later in an agitated liquid consisting of water and sodium per carbonate at $75^{\circ} \mathrm{C}$ for 4 hours. The resulting prototype needed 13.1 hours and 58.23 cubic centimetres of 'model material' and 56.67 cubic centimetres of 'support material'. After removing the support material, the final surface finish was improved by abrasion with P500 glass sandpaper according to the ISO 6344 regulation and the FEPA 43-1 and 43-2 2006 standards. Finally the mask was painted black for 
aesthetic reasons with a common spray-paint (Figure 8). No additional medical-grade coating was applied to the prototype. Two rubber strips served to attach the mask to the participant's face.

\section{Workflow evaluation}

Several verification processes were carried out throughout the explained workflow to analyse the suitability of the proposed methodology.

Firstly, the face meshes digitised from the 3dMD and Sense scanners were compared to analyse the appropriateness of a low-cost device for face scanning. The mesh files from the digitising process were loaded into the open source software MeshLab (MeshLab, Visual Computing Lab -ISI - CNR), version 1.3.2. After loading the meshes in their initial position, the comparison of the two meshes was carried out following a two-step process. In the first step, an Iterative Closest Point (ICP) algorithm was used to automatically align the two meshes. In short, this algorithm performed the best rigid transformation to one of the mesh -the movable mesh- in order to achieve a 'best fit' to the second mesh -the fixed mesh- within the same reference space.

Once the meshes were aligned, they were compared by means of the one-sided version of the Hausdorff Distance method. Hausdorff Distance measures how far two meshes placed on a three-dimensional space are from each other. The result of this method in MeshLab was a log window displaying -among others- the number of vertices computed and the average range between the two meshes. The computed distance values were also visualized using a color-coded 3D displacement map where identical regions between the two meshes received a Hausdorff Distance of zero and were indicated in red while the range of mismatches was coloured in yellow, green and blue.

Secondly, prior to sending the model to the 3D printer, a quality control assessment was performed using the deviation between the designed masks and the scans of the patient's faces to determine how closely the mask would fit. 
Later, the software viability was evaluated through feasibility tests with volunteers. Nine participants volunteered for the feasibility testing. They were male and female and ranged between 18 and 50 years old, and all of them except one, had no prior experience with Rhinoceros or Grasshopper and no relation to the medical field in terms of actually creating these kinds of splints. All the participants had some kind of engineering degree but their expertise differed (design, manufacturing, fluid mechanics, structures, etc.). The experiment was performed within 90 minutes. Before the test, the participants were asked to fill out a demographic questionnaire. In the first 30 minutes, the instructor introduced the purpose of the evaluation, and the tasks to be performed with DeMask software were illustrated step by step. In the second 30 minutes, the participants had a familiarization session with the platform where they were familiarised with DeMask and tried to model a mask by themselves but with the possibility of asking the instructor any query. Finally, in the last thirty minutes, the volunteers started the modelling of a new mask with the only help of a video tutorial and a short manual. Once the participants completed the experiment, they were asked to fill out a feasibility questionnaire in order to rate each step and comment on the advantages/disadvantages. The feasibility questionnaire followed a 5-point Likert Scale to evaluate each one of the steps within DeMask software.

Finally, the cost of the new methodology was compared against the conventional approach. For the new methodology, the 3dMD prototype cost was divided into four stages: Modelling, Additive Manufacturing, Materials and Post-processing following the proposal of Pereira et al.(Mello et al. 2009) but without including the energy consumption of the equipment. These costs considered that a regular practitioner will be the future user of the equipment/software and that he or she will have the proper skills to perform all the tasks within a normal time and without any issue. The modelling cost $\left(\mathrm{C}_{\mathrm{MOD}}\right)$ is given by the equation:

$$
C_{M O D}=\left(\frac{C_{H}}{N_{a m} \cdot H_{a v}}+\frac{C_{S}}{N_{a m} \cdot S_{a v}}\right) t_{M}+C_{p} \cdot t_{M}
$$

Where $\mathrm{C}_{\mathrm{H}}$ - Hardware cost: laptop plus scanner $(€), \mathrm{C}_{\mathrm{S}}$ - Software cost: Rhinoceros plus Grasshopper (€), $\mathrm{N}_{\mathrm{am}}$ - Amortization time for the hardware and the software equipment (years), $\mathrm{H}_{\mathrm{av}}$ 
- Hardware availability time per year (h), $\mathrm{S}_{\mathrm{av}}$ - Software availability time per year $(\mathrm{h}), \mathrm{t}_{\mathrm{M}}$ -

Practitioner's modelling time (h), $\mathrm{C}_{\mathrm{p}}$ - practitioner's cost per hour (€/h). The Additive

Manufacturing cost $\left(\mathrm{C}_{\mathrm{AM}}\right)$ is ruled by the equation:

$$
\mathrm{C}_{\mathrm{AM}}=\left(\frac{\mathrm{C}_{\mathrm{H}}}{\mathrm{N}_{\mathrm{am}} \cdot \mathrm{H}_{\mathrm{av}}}+\frac{12 \cdot \mathrm{C}_{\mathrm{MO}}}{\mathrm{H}_{\mathrm{av}}}\right) \mathrm{t}_{\mathrm{AM}}+\mathrm{C}_{\mathrm{p}} \cdot \mathrm{t}_{\mathrm{pAM}}
$$

Where $\mathrm{C}_{\mathrm{H}}$ - Hardware cost: printer $(€), \mathrm{N}_{\mathrm{am}}$ - Amortization time for the hardware and the software equipment (years), $\mathrm{H}_{\mathrm{av}}$ - Hardware availability time per year (h), $\mathrm{t}_{\mathrm{AM}}$ - Printing time (h), $\mathrm{C}_{\mathrm{p}}$ - practitioner's cost per hour $(€ / \mathrm{h}), \mathrm{C}_{\mathrm{MO}}$ - maintenance cost per month $(€ /$ month $)$ and $\mathrm{t}_{\mathrm{pAM}}-$ practitioner's time for printing process $(\mathrm{h})$. The material $\left(\mathrm{C}_{\mathrm{MAT}}\right)$ cost is given by:

$$
\mathrm{C}_{\mathrm{MAT}}=\frac{\mathrm{V}_{\mathrm{M}} \cdot \mathrm{P}_{\mathrm{M}}}{\mathrm{V}_{\mathrm{c}}}+\frac{\mathrm{V}_{\mathrm{S}} \cdot \mathrm{P}_{\mathrm{S}}}{\mathrm{V}_{\mathrm{c}}}
$$

Where $\mathrm{V}_{\mathrm{m}}$ - Model volume utilized $\left(\mathrm{cm}^{3}\right), \mathrm{P}_{\mathrm{m}}$ - specific cost per model material volume $(€)$, $\mathrm{V}_{\mathrm{s}}$ - Support volume utilized $\left(\mathrm{cm}^{3}\right), \mathrm{P}_{\mathrm{s}}$ - specific cost per support material volume $(€)$ and $\mathrm{V}_{\mathrm{c}}-$ model/support material volume per cartridge $\left(\mathrm{cm}^{3}\right)$. Finally, the post-processing cost $\left(\mathrm{C}_{\mathrm{PP}}\right)$ is the sum of resource cost and the specific cost per hour of operator's labour needed in this stage:

$$
\mathrm{C}_{\mathrm{PP}}=\left(\frac{\mathrm{C}_{\mathrm{H}}}{\mathrm{N}_{\mathrm{am}} \cdot \mathrm{H}_{\mathrm{av}}}\right) \mathrm{t}_{\mathrm{PP}}+\mathrm{C}_{\mathrm{s}}+\mathrm{C}_{\mathrm{p}} \cdot \mathrm{t}_{\mathrm{ppp}}
$$

Where $C_{H}$ - Hardware cost: washing machine (€), $N_{a m}$ - Amortization time for the hardware and the software equipment (years), $\mathrm{H}_{\mathrm{av}}$ - Hardware availability time per year (h), $\mathrm{t}_{\mathrm{pp}}$ - Postprocessing time (h), $C_{s}$ - Soap cost per washing $(€), C_{p}$ - practitioner's cost per hour $(€ / h)$ and $t_{p p p}-$ practitioner's time for post-processing (h).

The cost of the conventional mask was the sum of two concepts: manufacturing and materials. Similarly to the new methodology, it was considered average times and costs performed by a regular practitioner. The Manufacturing cost $\left(\mathrm{C}_{\mathrm{MAN}}\right)$ is ruled by the equation:

$$
\mathrm{C}_{\mathrm{MAN}}=\left(\frac{\mathrm{C}_{\mathrm{H}}}{\mathrm{N}_{\mathrm{am}} \cdot \mathrm{H}_{\mathrm{av}}}+\frac{12 \cdot \mathrm{C}_{\mathrm{MO}}}{\mathrm{H}_{\mathrm{av}}}\right) \mathrm{t}_{\mathrm{pMAN}}+\mathrm{C}_{\mathrm{p}} \cdot \mathrm{t}_{\mathrm{pMAN}}
$$

Where $C_{H}$ - Hardware cost: vacuum forming machine (€), $N_{a m}$ - Amortization time for the hardware equipment (years), $\mathrm{H}_{\mathrm{av}}$ - Hardware availability time per year (h), $\mathrm{C}_{\mathrm{p}}$ - practitioner's cost 
per hour $(€ / h)$ and $t_{\text {pMAN }}$ - practitioner's time for manufacture $(h)$. The material ( $\left.\mathrm{C}_{\mathrm{MAT}}\right)$ cost is given by:

$$
\mathrm{C}_{\mathrm{MAT}}=\mathrm{C}_{\mathrm{alg}}+\mathrm{C}_{\text {plas }}+\mathrm{C}_{\mathrm{den}}+\mathrm{C}_{\mathrm{PC}}
$$

Where $\mathrm{C}_{\mathrm{alg}}$ - Alginate cost per mask, $\mathrm{C}_{\mathrm{pla}}-$ Plaster bandages cost per mask, $\mathrm{C}_{\mathrm{den}}-$ Dental stone cost per mask and $\mathrm{C}_{\mathrm{PC}}-$ Polycarbonate cost per mask.

\section{Results}

The computed Hausdorff Distance is visualised in Figure 9, taking as reference the mesh with the highest number of vertices, that is, the Sense mesh (127,567 vertexes). The results of both scanners were very close in the face region: the right side of the face seemed to be closer than the left side, where the highest distance is $2.7 \mathrm{~mm}$. In the nose region, the distances are lower than $1 \mathrm{~mm}$.

In order to check the adjustment of the mask to the patient's face, the deviation of the mask surface with respect to the virtual face was also calculated (Figure 10). Negative values indicate that the mask is above the real geometry and consequently does not touch the face surface. In both cases, the largest deviations were located in the nose region with a negative value of $2 \mathrm{~mm}$. The 3dMD virtual mask had an average deviation of $0.18 \mathrm{~mm}$ by considering 17,044 points, whereas the Sense virtual mask presented an average value of $0.15 \mathrm{~mm}$ with 19,637 points. Such small deviations were almost unnoticeable for the volunteer, since he indicated that the adjustment of the mask was comfortable after printing the prototype.

The results of the feasibility questionnaire are presented in Figure 11. Six of the volunteers completed their mask within 10-20 minutes while the remaining three volunteers needed 30 minutes at least in their first attempt. The results of the feasibility questionnaire were quite satisfactory since users rated interactions above three in all the questions. According to these results, the lowest scores corresponded to the most difficult stages of the process, that is, the positioning of the face mesh and the proper selection of the curves to define the face mask. These lowest scores were related to the difficulty mentioned by some of the participants when managing the multi-window modelling 
environment of Rhinoceros. Finally, all the users agreed that they would have worked faster in successive modelling process: six of them just slightly faster and three much faster.

The partial and total cost of the new proposed approach is shown in Table 1. Equation (1) was used to calculate the modelling cost. In order to calculate the hardware cost per hour, it was considered a laptop computer and the 3dMD scanner that is 45,000€ worth with an amortization time of 5 years. The availability time per year for the equipment was 1650 hours. To calculate the software license cost, the same premise was adopted as for the laptop. A single license of Rhinoceros can be bought for $995 €$, whilst the Grasshopper plug-in is free. The practitioner's hourly rate was $45 €$ which corresponded to the maximum wage for a technician working at the university lab. This work assumed that the practitioner is able to model the customized mask in a maximum of 30 minutes with the help of DeMask software. The Additive Manufacturing cost was calculated using Equation (2). The AM printer cost 13,500€ and the monthly maintenance cost is $165 €$ according to the data provided by the supplier. Its availability is 1650 hours. The mask needed 13.1 hours for printing while the practitioner needed around 15 minutes to prepare the printing process. The same premise was adopted for the practitioner's wage per hour. The material cost during the AM process was also considered with the equation (3). Each model and support material cartridge has a volume of $655 \mathrm{~cm} 3$ and cost $165 €$ and $160 €$ respectively. The 3dMD mask was built with $58.23 \mathrm{~cm}^{3}$ of 'model material' and $56.67 \mathrm{~cm}^{3}$ of 'support material'. The post-processing cost is carried out with Equation (4). The cleaning machine was purchased at $1500 €$ and its availability was of 1650 hours. The time inside the cleaning machine was 4 hours to remove the support material by using a water and soap solution. The soap cost per process is $2 €$. It was measured that the practitioner needed around 6 minutes to place the mask and the soap sack in the inside of the cleaning machine before turning it on. The same premise was adopted for the practitioner's wage per hour. For the new approach final cost, the resulting cost of Equations (1), (2), (3) and (4) were summed up. The final cost was $109.43 €$. 
The same cost study was carried out with low-cost equipment (Table 2). Hence, considering a $750 €$ laptop and low-cost scanner like the Sense scanner (400€), the modelling cost would be 22.63€. In a similar way, the AM cost would decrease by considering a low-cost AM printer. The premises for this printer were fundamentally an attractive price and a better printing resolution than the HP printer. Among the different affordable possibilities in the market, the face mask was printed in the 'Voladora' FDM printer model from Tumaker (Tumaker, Oiartzun, Spain). It features a resolution of 200 microns, a head speed of $100 \mathrm{~mm} / \mathrm{s}$, prints in ABS as well and its price is $1500 €$. With this device and considering a lower maintenance cost per month (50€), the AM cost would decrease to 16.7€. Additionally, the low-cost printer uses cheaper ABS material: the cost of a model/support cartridge of 750 grams is around $30 €$ and $25 €$ respectively. This would reduce the material cost from $28.51 €$ to $9.49 €$. The post-processing cost involves the dissolving of the support material (HIPS) using d-limonene. No cleaning machine is needed, because the piece is simply immersed in a container filled with d-limonene. Considering all the steps, the total cost would be $55.32 €$.

The partial and total cost of the conventional approach is depicted in Table 3. These costs included the expenses of creating a similar mask, in terms of shape, number of transpiration holes, etc. The manufacturing cost was calculated with Equation (5). The vacuum forming machine for objects similar to face mask dimensions can be found for $1500 €$ with a maintenance per month of $25 €$. The amortization time for the machine is 5 years and its availability 1650 hours. The practitioner needed no less than 1.5 hours, for the entire process: 20 minutes for the alginate mould, 35 minutes for the dental stone replica and 35 minutes for the vacuum forming and the final details of the mask (borders, holes, etc.). The hourly wage remained 45€. The material cost included the necessary amount of alginate, plaster bandages, dental stone and Polycarbonate to build the mask. For the negative impression with alginate, 200 grams at a price of around 10€/kg was considered. A roll $2 \times 0.1 \mathrm{~m}$ of plaster bandages was needed to cover the alginate, $3 €$. For the positive impression, $3 \mathrm{~kg}$ of class III dental stone at $4.3 € / \mathrm{kg}$ was considered enough to fill the negative impression of the 
face. A LTT sheet of around $3.2 \times 350 \times 350 \mathrm{~mm}$ can be found for $5 €$. Summing up, the total cost of the mask with the conventional approach was $91.05 €$.

\section{Discussion}

This paper describes a novel methodology for the design and manufacture of a patient-specific face mask but several points of this work deserve discussion.

The first point of discussion is the scope of this paper. Although this work only considered protective masks for nose fractures, the proposed methodology can be extended to other specific face regions that need to be treated. This is the case, for instance, of shielding masks for cancer treatment (Deon J. de Beer et al. 2005) and hypertrophic scars as a result of burns (Powell et al. 1985). These face masks could be also designed following the proposed methodology since the scanning process and the printing process would not require any changes. With respect to the modelling step, the algorithm in Grasshopper would require few changes since new lines that cover the entire facial features should be drawn and the trimming lines should be adjusted to define the mask borders. The rest of the steps would remain identical.

With respect to feasibility testing, all the volunteers had some kind of engineering background and expertise with CAD which allowed them, in theory, become familiar faster with DeMask modelling environment more easily than a complete lay user with no engineering experience. Splinting practitioners, in general, are unlikely to have these CAD skills because they are not typically expected in their professional duties. Despite this different background, the results of the DeMask study indicated that it was simple to use and should not pose any significant difficulties for lay users. This hypothesis relies on the current behaviours of modern society, where people live surrounded by technological devices in their everyday life that need to be learnt and used, i.e. smartphones. This continued immersion in technological environments should allow practitioners to perform the feasibility test of DeMask software with a similar level of performance. 
Nevertheless, this hypothesis should be evaluated with usability tests where clinical practitioners verify the use of the new methodology.

The cost study of the new methodology presented the cost in a general scenario, where all machines, software, etc. need to be acquired. Particular cases were neglected but they can be easily implemented if, for instance, the practitioner already has a laptop suitable for the scanning, modelling and printing process, the cost of labour per hour is lower or the cost of splinting material is different. Regarding the cost of the new approach, it is true that the competitiveness of high-cost equipment is small in comparison to the traditional approach (109.43€ vs. 91.05€). However, with the current advances in low-cost technology, we have shown that the approach could prove cost effective (55.32€ vs. 91.05€). From the technical point of view, we have shown that geometric differences between surfaces captured with a high and a low-cost device is minimal and that the low-cost AM printer even has better printing properties than more expensive devices. Considering these two findings, and the total cost, we have discovered that this technological approach is completely affordable, less than two-thirds of the cost of the traditional approach, a very competitive price.

Regarding the user interface of Grasshopper, although the volunteers scored it well, DeMask software still has some limitations. The ambitious initial goal of developing a semi-automatic customization software together with the fact that Grasshopper offers few tools to represent straightforward menus would be a drawback in real practice. Nevertheless, this should present problems only in the learning process of DeMask software, since once the practitioner is familiar with the interface the process should allow him or her to design the mask in few minutes. Additionally, this relationship would also improve taking into account that incoming updates of Grasshopper will incorporate new tools to improve the interaction between the practitioner and the customization software for future versions. 


\section{Conclusions}

This study has corroborated that the use of an efficient modelling approach, in combination with low-cost digitising and AM devices, could be a real alternative to conventional practices when creating protective face masks. This study has shown that the scanning accuracy of a readily available, general purpose low-cost scanner was close to the quality of a dedicated high-cost face scanner, with a difference of less than 1 millimetre in the nose region. This study has also demonstrated that, following others works found in literature, a semi-automatic 3D modelling strategy can be planned to help clinical practitioners when designing customized face masks in a short time. Our feasibility test indicated that a face mask can be designed by a non-experienced user in 10 to 20 minutes. Additionally, this work indicates that this novel methodology may prove economically viable compared to the traditional approach when using affordable but high-quality scanners and 3D printers. Summarizing, this paper describes a novel methodology that shows some significant improvements in comparison to the traditional approach: it is less intrusive to the patient, it could be as much two-thirds of the cost and it allows the practitioner to customize patient's mask with a minimal effort.

\section{Acknowledgements}

Thanks to Luis Naval MD, head of Oral and Maxillofacial Surgery Department from Clinica Universidad de Navarra for his help and advices throughout this project. 


\section{References}

Aung, S., Ngim, R., and Lee, S., 1995. Evaluation of the laser scanner as a surface measuring tool and its accuracy compared with direct facial anthropometric measurements. Brithish Journal of Plastic Surgery 48, 551-558.

Bell, R. B., and Kindsfater, C. S., 2006. The Use of Biodegradable Plates and Screws to Stabilize Facial Fractures. Journal of Oral and Maxillofacial Surgery 64, 31-39.

Bibb, R., Freeman, P., Brown, R., Sugar, A., Evans, P., and Bocca, A., 2000. An investigation of three-dimensional scanning of human body surfaces and its use in the design and manufacture of prostheses. Proceedings of the Institution of Mechanical Engineers, Part H: Journal of Engineering in Medicine 214, 589-594.

Bibb, R., Bocca, A., and Hartles, F., 2004. Producing burns therapy conformers using non contact scanning and rapid prototyping. 6th International Symposium on Computer Methods in Biomechanics \& Biomedical Engineering, Madrid (Spain).

Boehmen, C., and Flynn, P., 2005. Accuraccy of 3D scanning technologies in a face scanning scenario. Fifth International Conference on 3-D Digital Imaging and Modeling, Ottawa (Canada), 310-317.

Chandra, A., Watson, J., Rowson, J. E., Holland, J., Harris, R. A., and Williams, D. J., 2004. Application of rapid manufacturing techniques in support of maxillofacial treatment: evidence of the requirements of clinical applications. Proceedings of the I MECH E, Part B - Journal of Engineering Manufacture 219, 469-475.

Deon J. de Beer, Michéle Truscott, Gerrie J. Booysen, Ludrick J. Barnard, and Jakobus G. van der Walt, 2005. Rapid manufacturing of patient-specific shielding masks using RP in parallel with metal spraying. Rapid Prototyping Journal 11, 298-303.

Faustini, M. C., Neptune, R. R., Crawford, R. H., and Stanhope, S. J., 2008. Manufacture of Passive Dynamic ankle-foot orthoses using selective laser sintering. IEEE Transactions on Biomedical Engineering 55, 784-790.

Ghoseiri, K., Ghoseiri, G., Bavi, A., and Ghoseiri, R., 2013. Face-protective orthosis in sportrelated injuries. Prosthetics and Orthotics International 0, 1-3.

Hogg, N. J. V., Stewart, T. C., Armstrong, J. E. A., and Girotti, M. J., 2000. Epidemiology of Maxillofacial Injuries at Trauma Hospitals in Ontario, Canada, Between 1992 and 1997. Journal of Trauma-Injury Infection \& Critical Care 49, 425-432.

Le, B. T., Dierks, E. J., Ueeck, B. A., Homer, L. D., and Potter, B. F., 2001. Maxillofacial injuries associated with domestic violence. Journal of Oral and Maxillofacial Surgery 59, 1277-1283.

Lin, J. T., and Nagler, W., 2003. Use of surface scanning for creation of transparent facial orthoses: A report of two cases. Burns 29, 599-602.

Locke, S., Smith, S., Szeliski-Scott, B., and Lemaire, E. D., 1991. A clear polycarbonate face mask for the treatment of hyperthropic scars. Journal of Prosthetics and Orthotics 3, 182-190.

Mavroidis, C., Ranky, R. G., Sivak, M. L., Patritt, B. L., DiPisa, J., Caddle, A., Gilhooly, K., Govoni, L., Sivak, S., Lancia, M., Drillio, R., and Bonato, P., 2011. Patient specific ankle-foot orthoses using rapid prototyping. Journal of NeuroEngineering and Rehabilitation 2,

Mello, C. H. P., Martins, R. C., Parra, B. R., Pamplona, E. d. O., Salgado, E. G., and Seguso, R. T., 2009. Systematic proposal to calculate price of prototypes manufactured through rapid prototyping and FDM 3D printer in a university lab. Rapid Prototyping Journal 16, 411-416.

Mondin, V., Rinaldo, A., and Ferlito, A., 2005. Management of nasal bone fractures. American Journal of Otolaryngology 26, 181-185.

Palousek, D., Rosicky, J., Koutny, D., Stoklasek, P., and Navrat, T., 2014. Pilot study of the wrist orthosis design process. Rapid Prototyping Journal 10, 27-32. 
Pallari, J. H., Dalgarno, K. W., and Woodburn, J., 2010. Mass customization of foot orthoses for rheumatoid arthritis using selective laser sintering. IEEE Transactions on Biomedical Engineering 57, 1750-1756.

Paterson, A. M. J., 2013. Digitisation of the splinting process: exploration and evaluation of a Computer Aided Design approach to support Additive Manufacture. Loughborough University,

Powell, B. W. E. M., Haylock, C., and Clarke, J. A., 1985. A semi-rigid transparent face mask in the treatment of postburn hypettrophic scars. British Journal of Plastic Surgery 38, 561-566.

Rivers, E. A., Strate, R. G., and Solem, L. D., 1979. The transparent face mask. American Journal of Occupational Therapy 33, 108-113.

Sanghera, B., Naique, S., Papaharilaou, Y., and Amis, A., 2001. Preliminary study of rapid prototype medical models. Rapid Prototyping Journal 7, 275-284.

Tanaka, N., Hayash, S., Amagasa, T., and Kohama, G.-I., 1996. Maxillofacial fractures sustained during sports. Journal of Oral and Maxillofacial Surgery 54, 715-719. 


\section{Tables}

\begin{tabular}{|c|c|c|c|}
\hline Name & Description & Units & Value \\
\hline $\mathrm{C}_{\text {MOD }}$ & Modelling cost & $€$ & 25.29 \\
\hline $\mathrm{C}_{\mathrm{H}}$ & Laptop + scanner cost & $€$ & 45000 \\
\hline $\mathrm{C}_{\mathrm{s}}$ & Single software license cost & $€$ & 995 \\
\hline $\mathrm{C}_{\mathbf{p}}$ & Practitioner cost per hour & $€ / h$ & 45 \\
\hline $\mathrm{H}_{\mathrm{av}}$ & Laptop availability time per year & h & 1650 \\
\hline $\mathrm{T}_{\mathbf{M}}$ & Practitioner's modelling time & $\mathrm{h}$ & 0.5 \\
\hline $\mathrm{N}_{\mathrm{am}}$ & Amortization time for hardware and software equipment & year & 5 \\
\hline $\mathbf{C}_{\mathrm{AM}}$ & Additive Manufacturing cost & $€$ & 48.41 \\
\hline $\mathrm{T}_{\mathrm{AM}}$ & Model printing time & h & 13.1 \\
\hline $\mathrm{C}_{\text {Mo }}$ & Cost maintenance per month & $€ /$ month & 165 \\
\hline $\mathrm{C}_{\mathbf{H}}$ & Printer price & $€$ & 13500 \\
\hline $\mathrm{H}_{\mathrm{av}}$ & Printer availavility per year & h & 1650 \\
\hline $\mathrm{C}_{\mathbf{p}}$ & Practitioner cost per hour & $€ / h$ & 45 \\
\hline$t_{\text {pAM }}$ & Practitioner's manufacturing time & $\mathrm{h}$ & 0.25 \\
\hline $\mathrm{C}_{\mathrm{MAT}}$ & Material cost & $€$ & 28.51 \\
\hline $\mathrm{V}_{\mathbf{M}}$ & Model volume utilized & $\mathrm{cm} 3$ & 58.23 \\
\hline $\mathrm{P}_{\mathbf{M}}$ & Specific cost per model material volume & $€$ & 165 \\
\hline $\mathrm{V}_{\mathrm{S}}$ & Support volume utilized & $\mathrm{cm} 3$ & 56.67 \\
\hline $\mathrm{V}_{\mathrm{C}}$ & Model/support material volume per cartridge & $\mathrm{cm} 3$ & 655 \\
\hline $\mathrm{P}_{\mathbf{C}}$ & Specific cost per support material volume & $€$ & 160 \\
\hline $\mathrm{C}_{\mathrm{pp}}$ & Post-processing cost & $€$ & 7.23 \\
\hline $\mathrm{C}_{\mathbf{H}}$ & Cleaning machine price & $€$ & 1500 \\
\hline $\mathrm{H}_{\mathrm{av}}$ & Cleaning machine availability per year & h & 1650 \\
\hline$t_{p p}$ & Mask permanence time inside the cleaning machine & h & 4 \\
\hline $\mathrm{C}_{\mathrm{s}}$ & Soap cost per washing time at post processing & $€$ & 2 \\
\hline $\mathrm{C}_{\mathbf{p}}$ & Practitioner cost per hour & $€ / h$ & 45 \\
\hline $\mathrm{T}_{\mathbf{p p p}}$ & Practitioner's post processing time & $\mathrm{h}$ & 0.1 \\
\hline Total & & $€$ & 109.43 \\
\hline
\end{tabular}

Table 1: New approach cost with high-cost equipment (3dMD scanner plus HP DesignJet Color 3D printer) 


\begin{tabular}{|c|c|c|c|}
\hline Name & Description & Units & Value \\
\hline $\mathrm{C}_{\text {MOD }}$ & Modelling cost & $€$ & 22.63 \\
\hline $\mathrm{C}_{\mathrm{H}}$ & Laptop + scanner cost & $€$ & 1150 \\
\hline $\mathrm{C}_{\mathrm{s}}$ & Single software license cost & $€$ & 995 \\
\hline $\mathrm{C}_{\mathbf{p}}$ & Practitioner cost per hour & $€ / h$ & 45 \\
\hline $\mathrm{H}_{\mathrm{av}}$ & Laptop availability time per year & h & 1650 \\
\hline $\mathrm{T}_{\mathrm{M}}$ & Practitioner's modelling time & $\mathrm{h}$ & 0.5 \\
\hline $\mathrm{N}_{\mathrm{am}}$ & Amortization time for hardware and software equipment & year & 5 \\
\hline $\mathrm{C}_{\mathrm{AM}}$ & Additive Manufacturing cost & $€$ & 16.7 \\
\hline $\mathrm{T}_{\mathrm{AM}}$ & Model printing time & $\mathrm{h}$ & 10 \\
\hline $\mathrm{C}_{\text {мо }}$ & Cost maintenance per month & $€ /$ month & 50 \\
\hline $\mathrm{C}_{\mathbf{H}}$ & Printer price & $€$ & 1500 \\
\hline $\mathrm{H}_{\mathrm{av}}$ & Printer availavility per year & h & 1650 \\
\hline $\mathrm{C}_{\mathbf{p}}$ & Practitioner cost per hour & $€ / h$ & 45 \\
\hline$t_{\text {pAM }}$ & Practitioner's manufacturing time & $\mathrm{h}$ & 0.25 \\
\hline $\mathrm{C}_{\text {MAT }}$ & Material cost & $€$ & 9.49 \\
\hline $\mathrm{V}_{\mathbf{M}}$ & Model volume utilized & Grams & 78 \\
\hline $\mathrm{P}_{\mathrm{M}}$ & Specific cost per model material volume & $€$ & 30 \\
\hline $\mathrm{V}_{\mathrm{s}}$ & Support volume utilized & Grams & 191 \\
\hline $\mathrm{V}_{\mathrm{C}}$ & Model/support material volume per cartridge & Grams & 750 \\
\hline $\mathrm{P}_{\mathrm{C}}$ & Specific cost per support material volume & $€$ & 25 \\
\hline $\mathrm{C}_{\mathrm{pp}}$ & Post-processing cost & $€$ & 6.5 \\
\hline $\mathrm{C}_{\mathrm{H}}$ & Container price & $€$ & 10 \\
\hline $\mathrm{H}_{\mathrm{av}}$ & Container availability per year & $\mathrm{h}$ & 1650 \\
\hline$t_{p p}$ & Mask permanence time inside the container & $\mathrm{h}$ & 4 \\
\hline $\mathrm{C}_{\mathrm{s}}$ & D-limonene per washing time at post processing & $€$ & 2 \\
\hline $\mathrm{C}_{\mathbf{p}}$ & Practitioner cost per hour & $€ / h$ & 45 \\
\hline $\mathrm{T}_{\text {ppp }}$ & Practitioner's post processing time & $\mathrm{h}$ & 0.1 \\
\hline Total & & $€$ & 55.32 \\
\hline
\end{tabular}

Table 2: New approach cost with low-cost equipment (Sense scanner plus 'Voladora' printer) 


\begin{tabular}{llcr}
\hline Name & Description & Units & Value \\
\hline $\mathbf{C}_{\text {MAN }}$ & Manufacturing cost & $€$ & $\mathbf{6 8 . 0 5}$ \\
$\mathrm{C}_{\mathrm{H}}$ & Vacuum forming machine & $€$ & 1500 \\
$\mathrm{C}_{\mathrm{p}}$ & Practitioner's cost per hour & $€ / \mathrm{h}$ & 45 \\
$\mathrm{H}_{\mathrm{av}}$ & Vacuum forming availability time per year & $\mathrm{h}$ & 1650 \\
$\mathrm{C}_{\mathrm{MO}}$ & Cost maintenance per month & $€ / \mathrm{h}$ & 25 \\
$\mathrm{t}_{\mathrm{pMAN}}$ & Practitioner's processing time & $\mathrm{h}$ & 1.5 \\
$\mathrm{~N}_{\mathrm{am}}$ & Amortization time for hardware and software equipment & year & 5 \\
\hline $\mathrm{C}_{\mathbf{M A T}}$ & Material cost & $€$ & $\mathbf{2 3 . 0 0}$ \\
$\mathrm{C}_{\mathrm{alg}}$ & Alginate & $€$ & 2 \\
$\mathrm{C}_{\text {pla }}$ & Plaster Bandages & $€$ & 3 \\
$\mathrm{C}_{\mathrm{den}}$ & Dental Stone & $€$ & 13 \\
$\mathrm{C}_{\mathrm{PC}}$ & Polycarbonate sheet & $€$ & 5 \\
\hline Total & & $€$ & $\mathbf{9 1 . 0 5}$ \\
\hline
\end{tabular}

Table 3: Conventional approach cost 


\section{Figure captions}

Figure 1 Methodology workflow for obtaining the face mask

Figure 2 Digitising process of the volunteer's face with the 3dMD face scanner (a) and the Sense scanner (b)

Figure 3 Volunteer's virtual face after digitising with the 3dMD face scanner (a) and the Sense scanner (b)

Figure 4 Part of DeMask algorithm within Grasshopper showing the user interface for the second step of the CAD modelling process

Figure 5 First stages of the modelling process: straight lines over the working area (a), lines projected on the mesh (b) surface from projected lines (d) and curve to change the mask borders (d and e)

Figure 6 Mask with two holes for the eyes (a) a single hole (b) and two holes opened in the lateral (c)

Figure 7 Different hole patterns: circular (a), elliptical (b) and rectangular (c)

Figure 8: Physical prototype of the 3dMD face mask. As is after printing (a), after removing the support material (b) and after sanding and painting (c)

Figure 9: Hausdorff Distance for the face meshes captured with the 3dMD face scanner and the Sense scanner

Figure 10: Surface deviation in mm for the mask-3dMD face scanner and (a) and mask-Sense scanner (b) combinations

Figure 11 Feasibility responses. Q1 corresponds to easiness when importing the face, Q2 corresponds to positioning of the face mesh, Q3 corresponds to easiness when adjusting the curves to define the mask, Q4 corresponds to the adjustment of the mask boundaries, Q5 corresponds to selection of the mask type, Q6 corresponds to the buckles and Q7 corresponds to perspiration holes. 


\section{Figures}

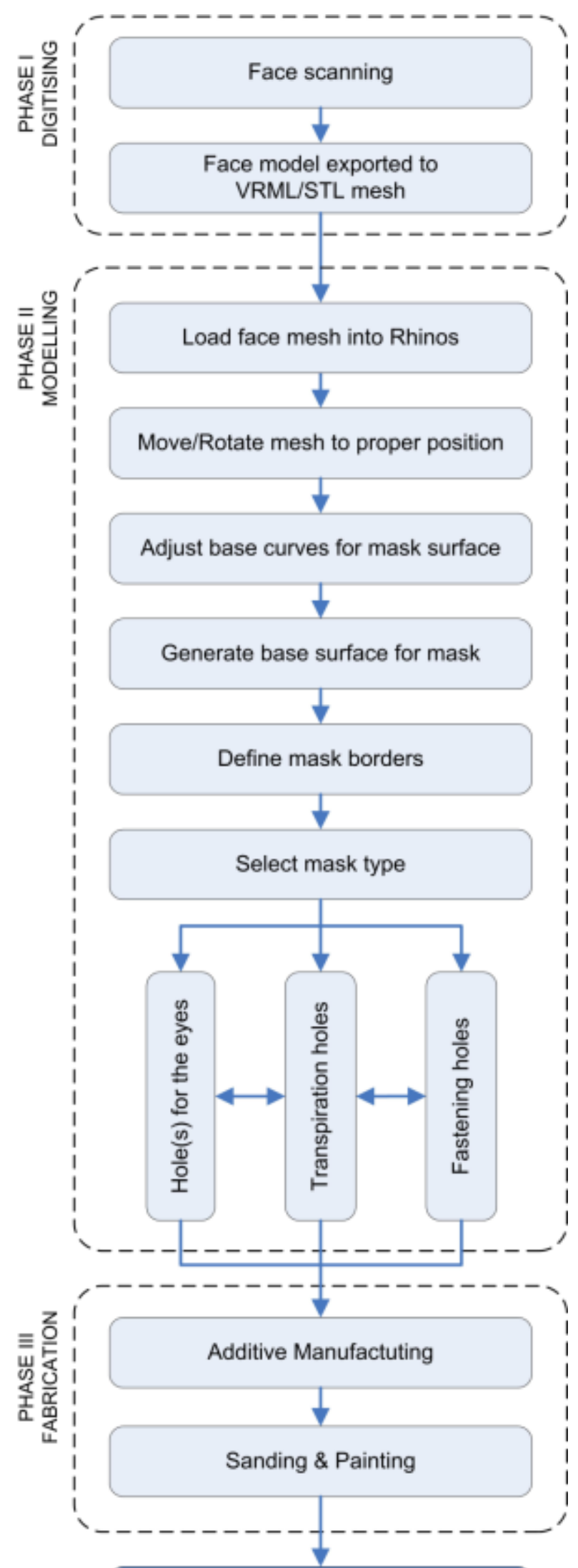

New Face Mask

Figure 1 


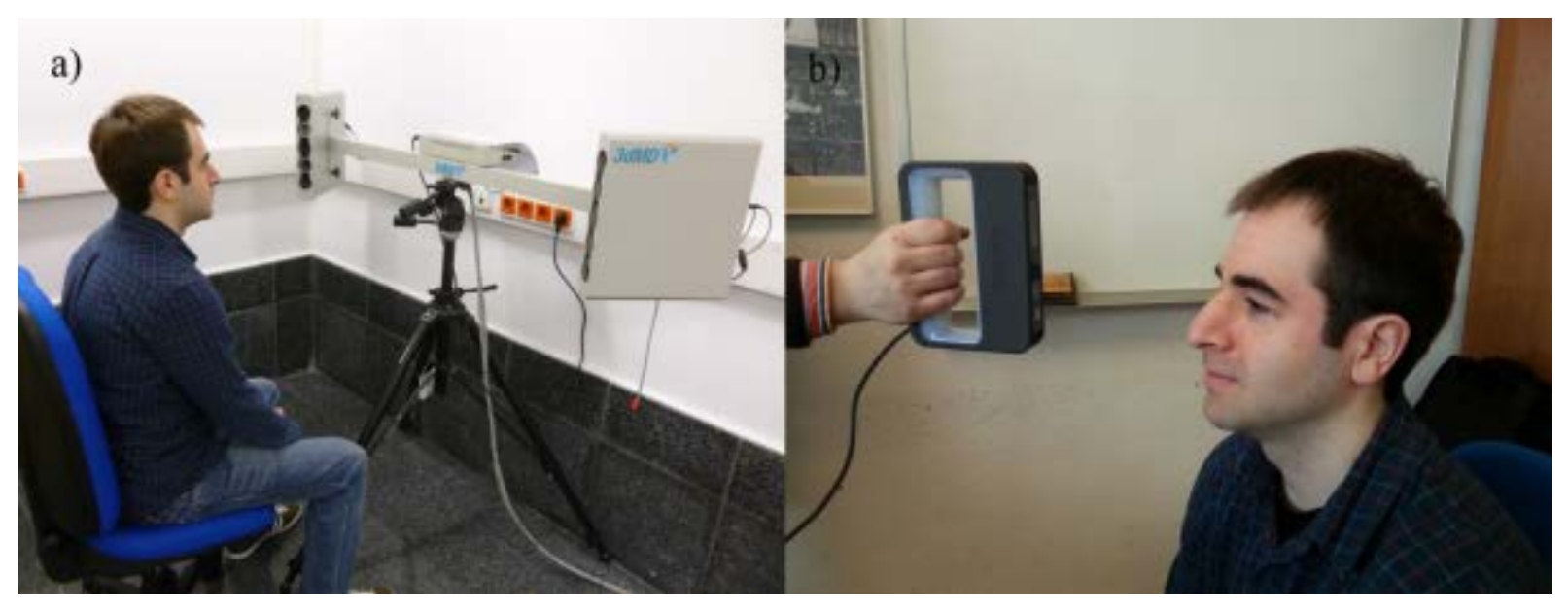

Figure 2

a)

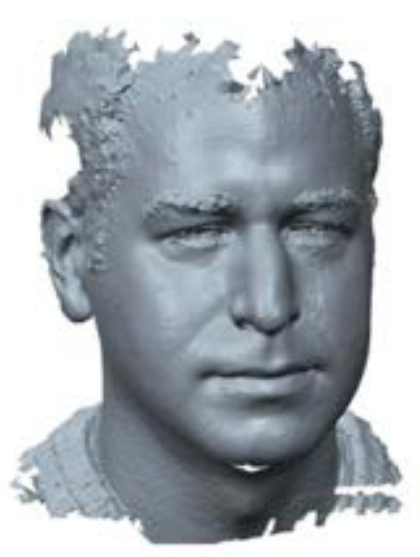

b)

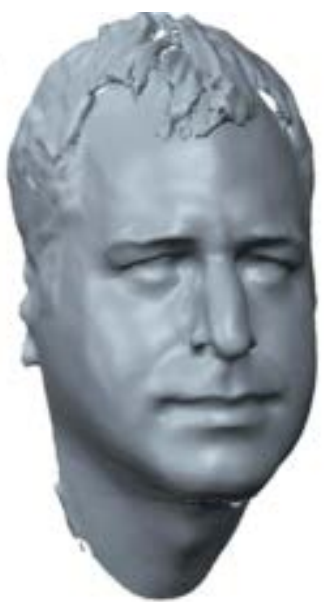

Figure 3

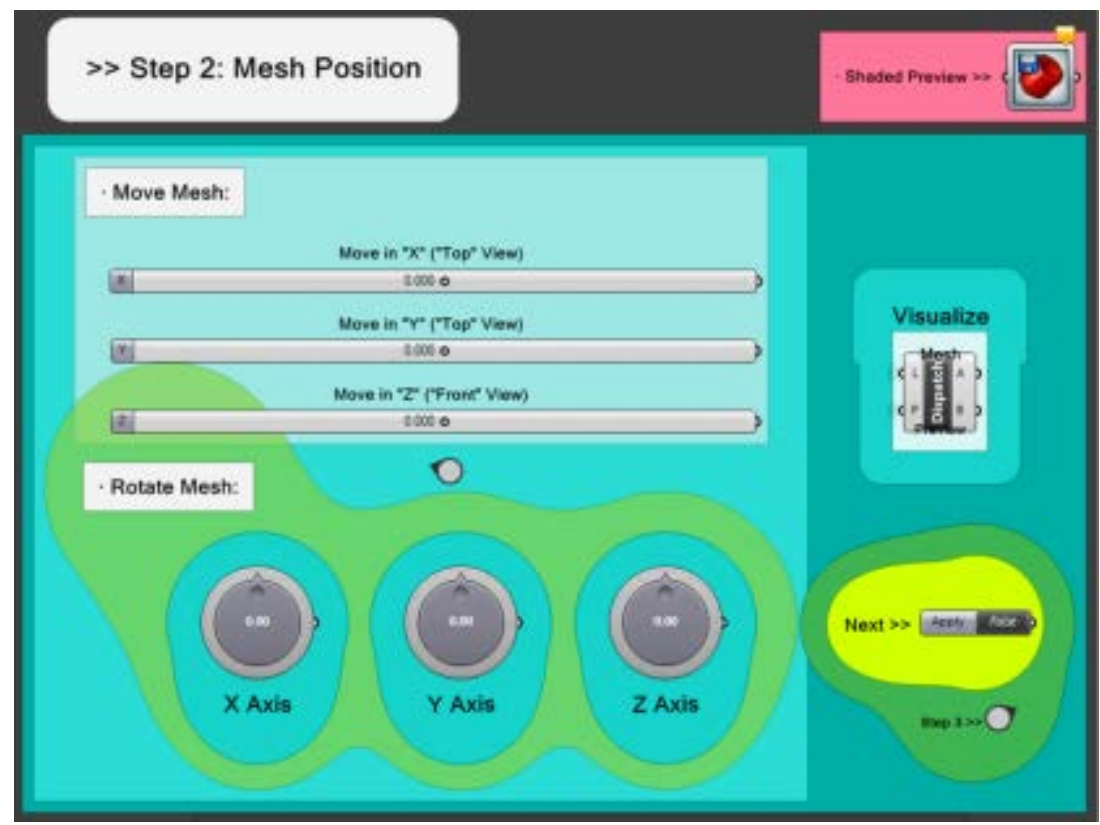

Figure 4 


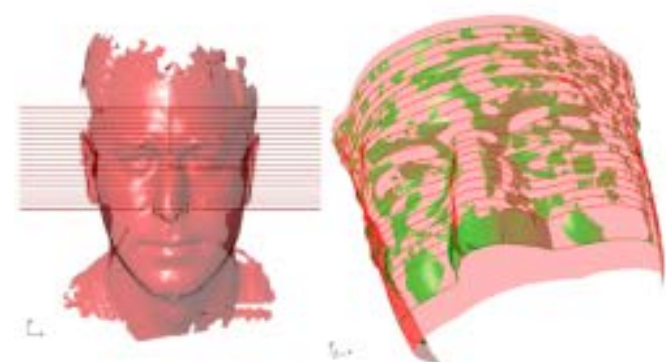

a)

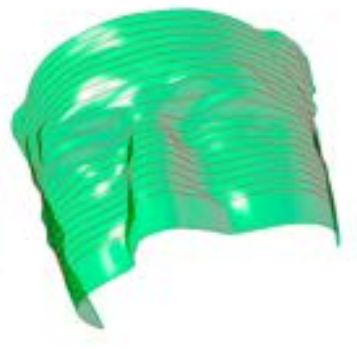

c)

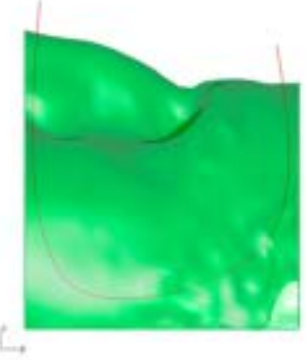

d)

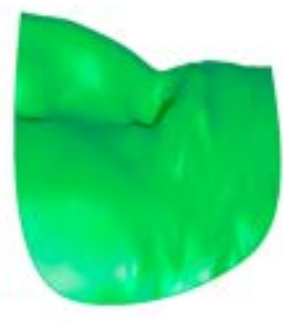

e)

Figure 5

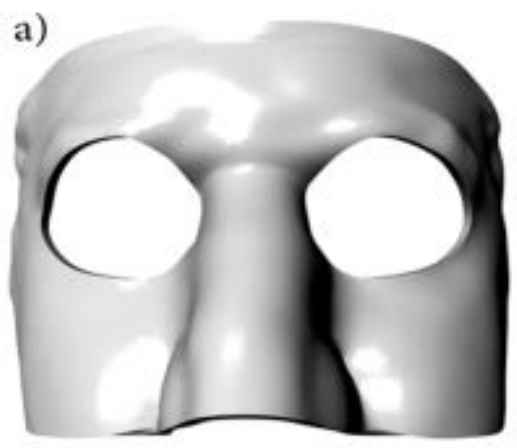

b)

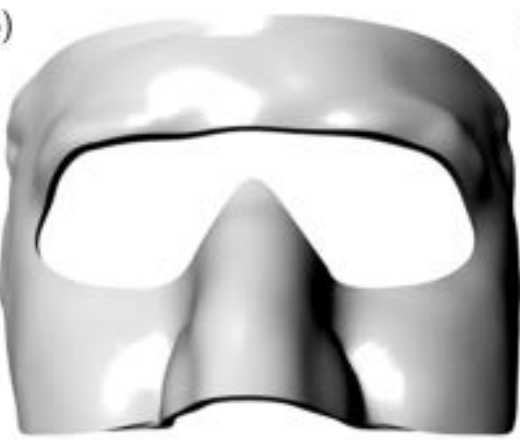

c)

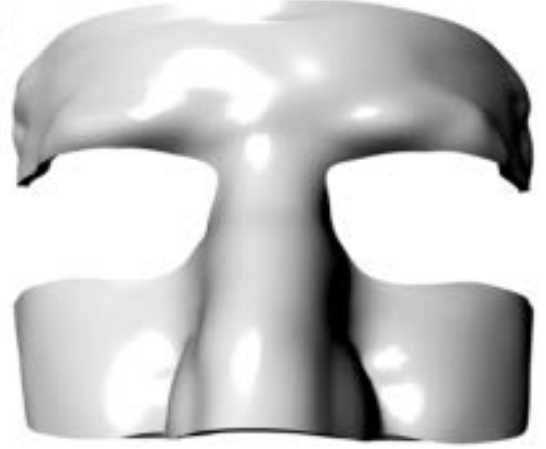

Figure 6

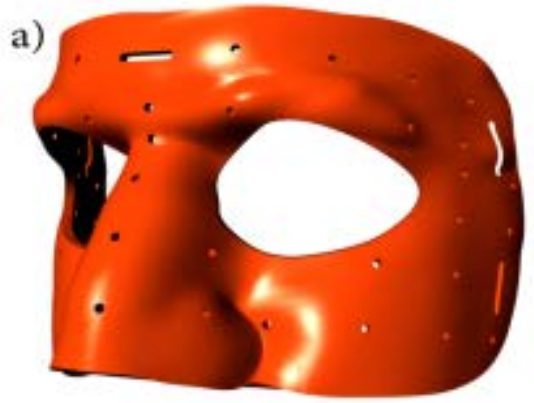

b)

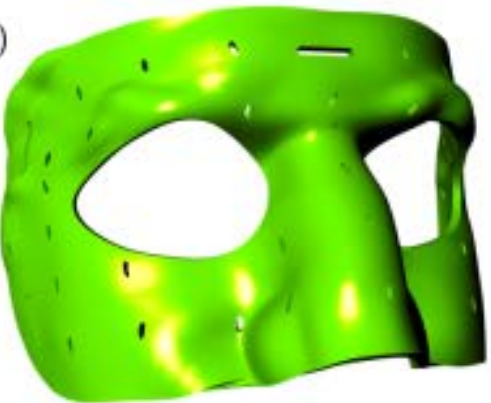

c)

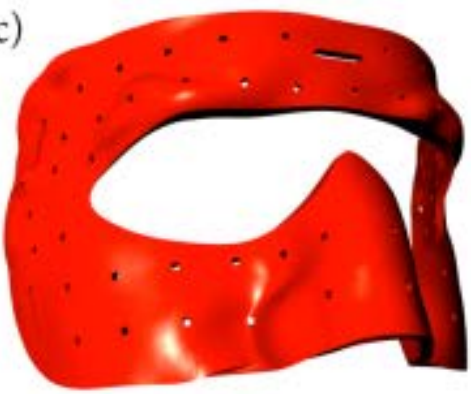

Figure 7
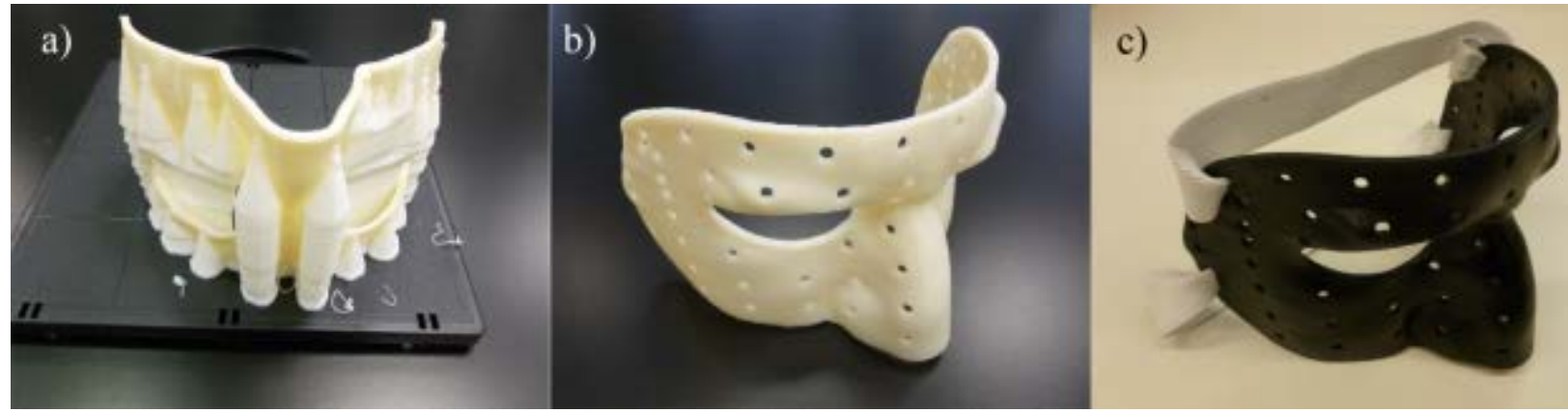

Figure 8 


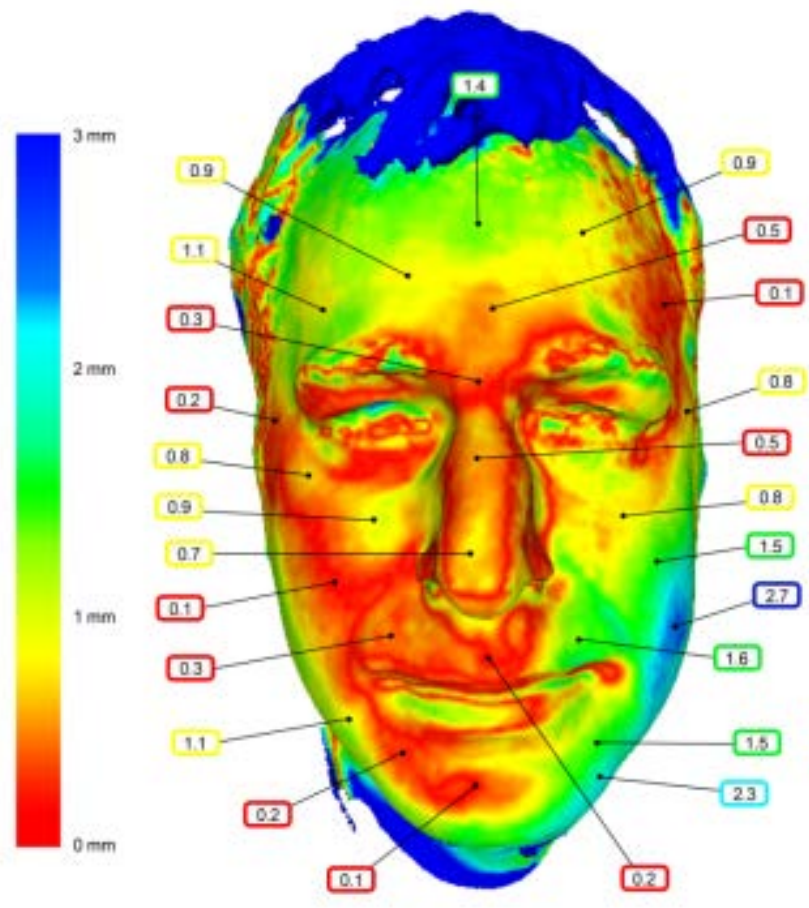

Figure 9

a)

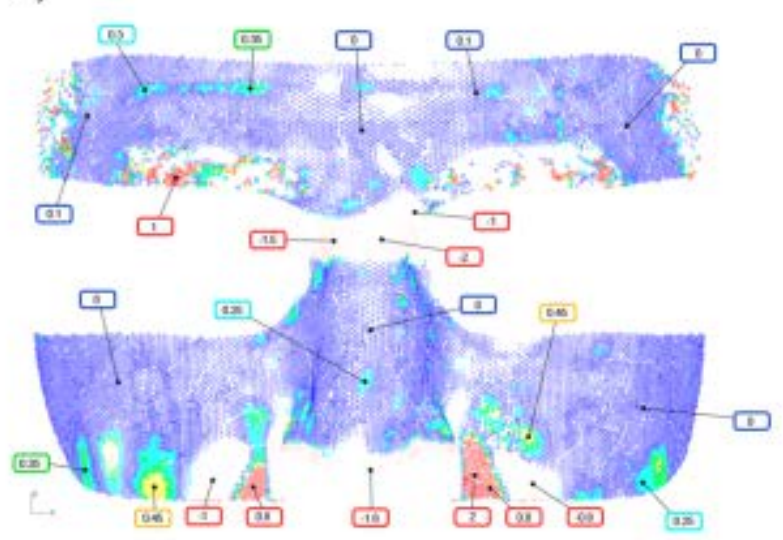

b)
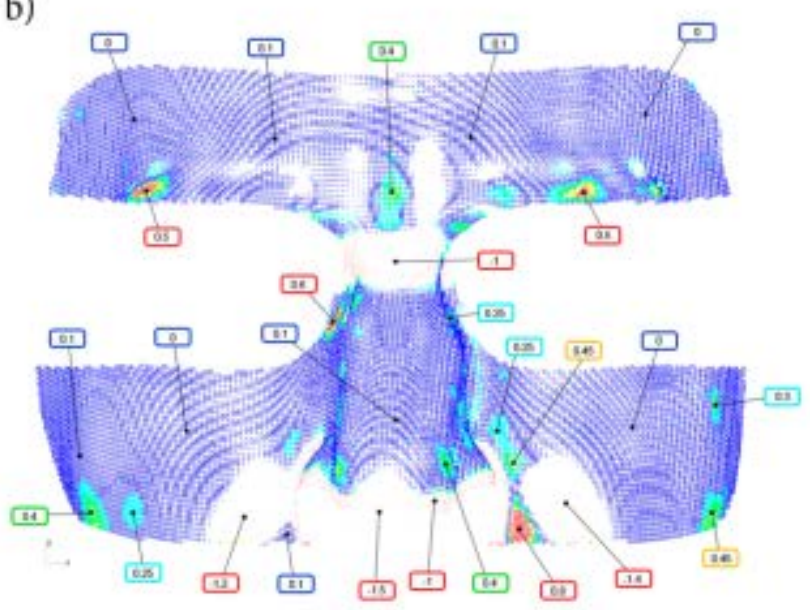

Figure 10 


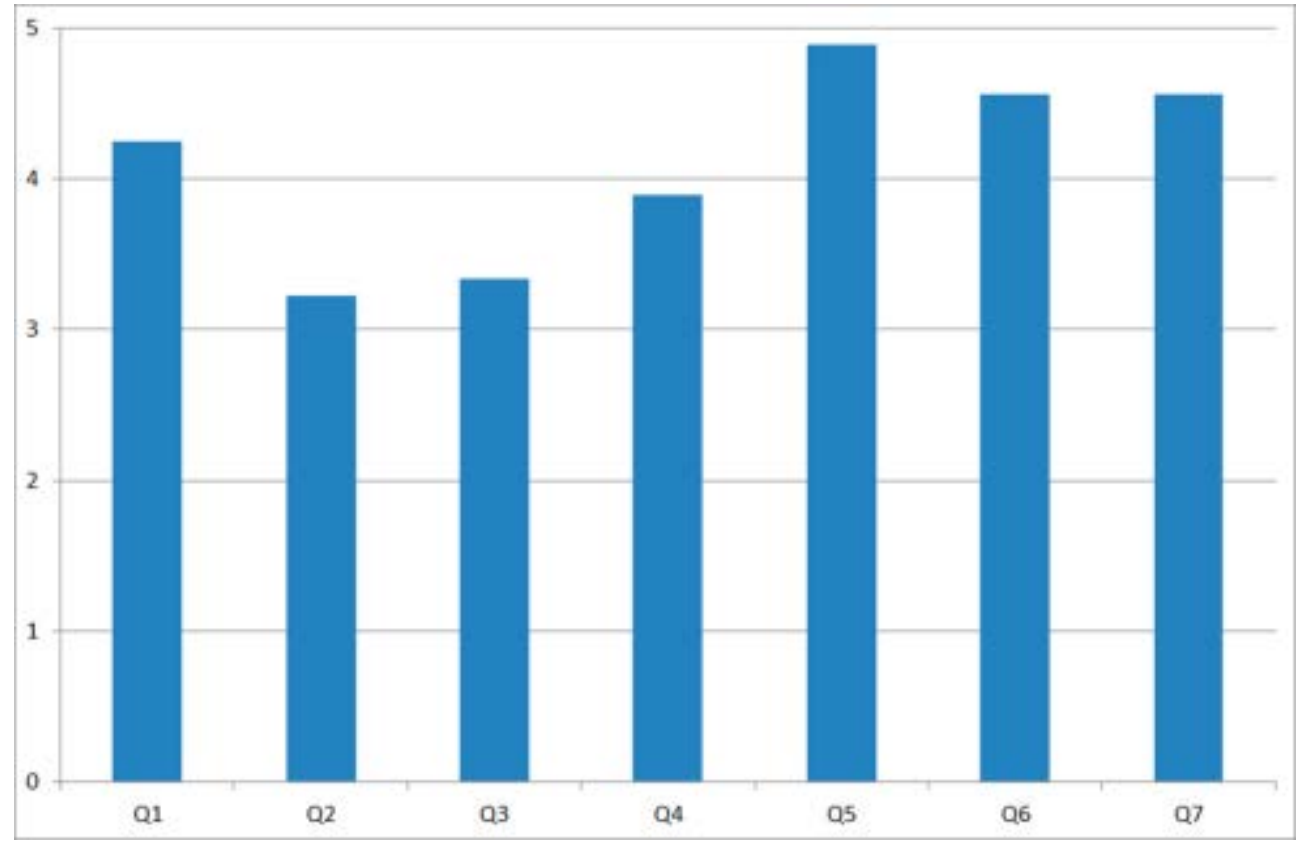

Figure 11 